\title{
Usefulness of Ultrasound-Guided Lower Extremity Nerve Blockade in Surgery for Patellar Fracture
}

\author{
Young-Mo Kim, MD, Chan Kang, MD, Yong-Bum Joo, MD, Kyu-Ung Yeon, MD, Dong-Hun Kang, MD, and \\ Il-Young Park, MD \\ Department of Orthopaedic Surgery, Chungnam National University Hospital, Daejeon, Korea
}

Purpose: To evaluate the usefulness of ultrasound-guided nerve blockade in patellar fracture surgery.

Materials and Methods: Twenty-three patients who underwent metal fixation under ultrasound-guided lower extremity blockade after diagnosis of patellar fracture from July 2011 to June 2012 were enrolled in this study. Under ultrasound guidance, femoral nerve, lateral femoral cutaneous nerve, obturator nerve, and sciatic nerve blockades were performed. For evaluation of anesthesia, interference with overall surgery, such as intraoperative knee pain and tourniquet pain, was checked. Individual anesthetic complications, satisfaction with nerve blocks, and choice of future anesthesia method were investigated.

Results: Nineteen patients underwent surgery without any pain and 4 patients with mild pain. Satisfaction was excellent in 17 patients, good in 5, and unsatisfactory in 1 . No complications such as infection or nerve injury occurred. In terms of selection of future anesthesia, 22 patients chose a nerve blockade of the lower extremity under ultrasound guidance, and one chose general anesthesia.

Conclusions: Overall, ultrasound-guided nerve block of the lower extremity for patellar fracture surgery showed satisfactory results. Therefore, it could be a useful method to prevent complications associated with general or spinal anesthesia.

Keywords: Patella, Fracture, Ultrasound-guided, Nerve block

\section{Introduction}

In orthopedic surgery, various anesthetic methods such as general, regional (epidural, spinal, intravenous, and peripheral nerve blocks) and local anesthesia are applied ${ }^{1-3)}$. However, it has been reported that general or spinal anesthesia in lower extremity operation among advanced age patients lead to mortality in 15 of 10,000 patients and there is a possibility of various complications, such as postoperative pain, respiratory problems, headache, hypotension, and urinary retention ${ }^{4)}$. On the contrary, peripheral

Received September 15, 2014; Revised (1st) December 28, 2014; (2nd) January 28, 2015; Accepted March 26, 2015

Correspondence to: Yong-Bum Joo, MD

Department of Orthopaedic Surgery, Chungnam National University

Hospital, 282 Munhwa-ro, Jung-gu, Daejeon 301-721, Korea

Tel: +82-42-338-2482, Fax: +82-42-338-2480

E-mail: longman76@hanmail.net

This is an Open Access article distributed under the terms of the Creative Commons Attribution Non-Commercial License (http://creativecommons.org/licenses/by-nc/4.0/) which permits unrestricted non-commercial use, distribution, and reproduction in any medium, provided the original work is properly cited. nerve block has been associated with much less complications. It is also an efficacious way for postoperative pain control and requires no fasting. Therefore, nerve block has acquired a larger role in orthopedic surgery ${ }^{2,3)}$.

Many studies reported on the lower-extremity nerve block using evoked paresthesia nerve block, neurostimulator-guided nerve block, ultrasound-guided nerve block, etc ${ }^{2,3,-8}$. However, most of these studies concern regional anesthesia during foot or ankle surgery. Shaw et al. ${ }^{9)}$ reported on anterior cruciate ligament reconstruction using the hamstring tendon under regional anesthesia, but femorosciatic nerve block and spinal anesthesia were also performed. Many studies have been published regarding the usefulness of nerve block in knee surgery, but postoperative pain management was a matter of concern ${ }^{10-12}$. Since knee has a much more complicated nerve distribution compared with calf or ankle, nerve block anesthesia has been rarely attempted to avoid nerve injury. The incidence of major complications resulting in permanent nerve damage has been reported as $1.5 \mathrm{in} 10,000^{13}$.

However, we hypothesized that if the nerves distributed in the knee could be precisely blocked under the ultrasound guidance, 
anesthesia for surgery could be achieved. Thus, we performed patellar fracture surgery (a common knee region surgery) after nerve block using ultrasound guidance and analyzed the results to investigate the safety and usefulness of ultrasound-guided nerve block.

\section{Materials and Methods}

\section{Study Subjects}

We included 23 patients who chose nerve block as an anesthetic method over general and spinal anesthesia among patients scheduled for surgery under the diagnosis of patellar fracture from July 2011 to June 2012. This study was conducted with approval of our hospital's Institutional Review Board (IRB number: 2014-11010). We received informed consent on the anesthesia method from all patients. Exclusion criteria were 1) fractures in areas besides the patella; 2) perineural hematoma that was confirmed before anesthesia to have been caused by an underlying disease (idiopathic thrombocytopenic purpura, chronic liver disease, etc.) or drugs (aspirin, clopidogrel, warfarin, etc.); 3) a local infection or abscess near the nerve blockade injection area; 4) a history of psychological disease; 5) a history of excessive anxiety of injections; 6) a history of allergy to local anesthetic drugs; 7) patient uncooperative with local anesthesia; and 8) patient's refusal of the nerve block method. The average age at the time of operation was 52.4 years (range, 18 to 85 years), and there were 15 males and 8 females. The trauma mechanisms were loss of footing in 11, vehicle accidents in 10 (4 drivers and 6 pedestrians), and sports injury in 2. Additional fractures in other areas were not observed
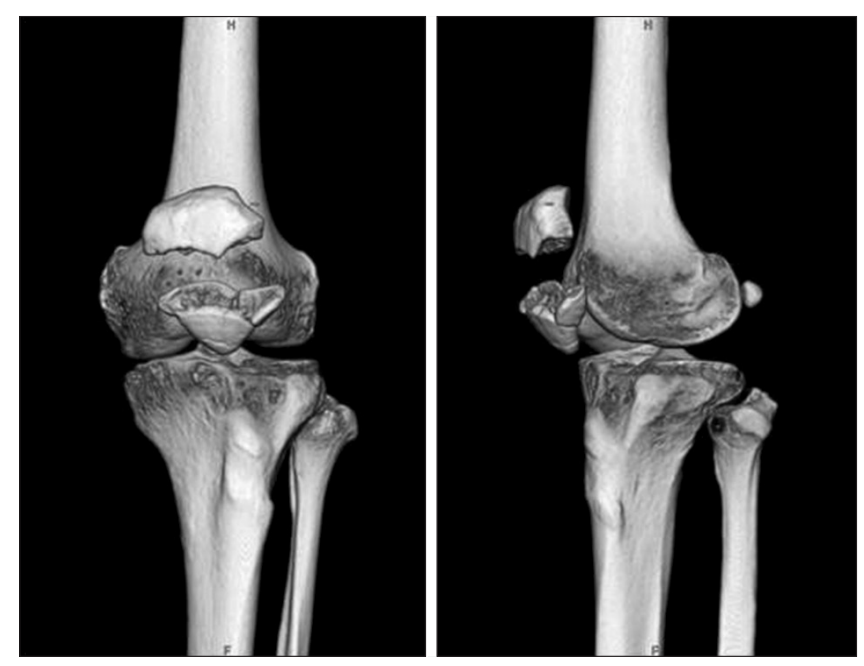

Fig. 1. Three-dimensional reconstructed computed tomography images showing displaced transverse patellar fractures without other fractures around the knee. in any of the patents. Nineteen patients had transverse fractures and four had vertical fractures (Fig. 1). Twenty were closed fractures and 3 were open fractures. There were three cases with each of the 1,2, and $3 \mathrm{~A}$ fractures categorized according to the Gustilo and Anderson classification. The operation involved tension-band wiring with open reduction in 17 patients (Figs. 2 and 3), screw or K-wire fixation with open reduction in 4 , and screw fixation with closed reduction in 2 (Table 1).

\section{Research Methods}

Under ultrasound guidance, the femoral nerve, lateral femoral

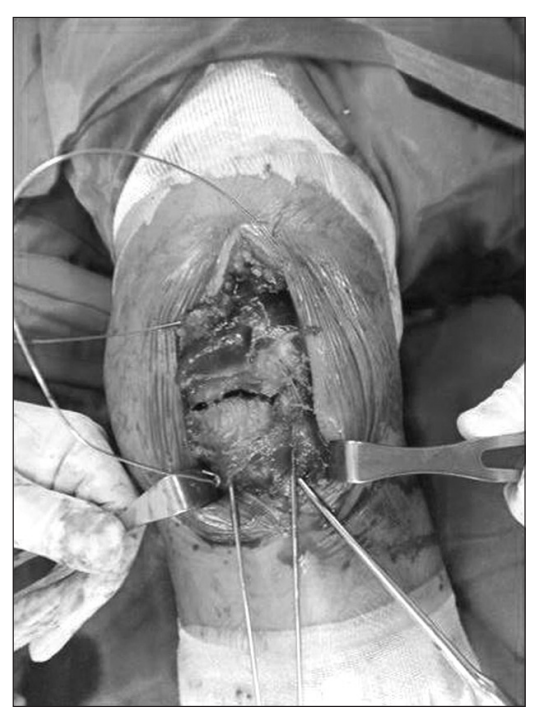

Fig. 2. Intraoperative photograph of the knee.
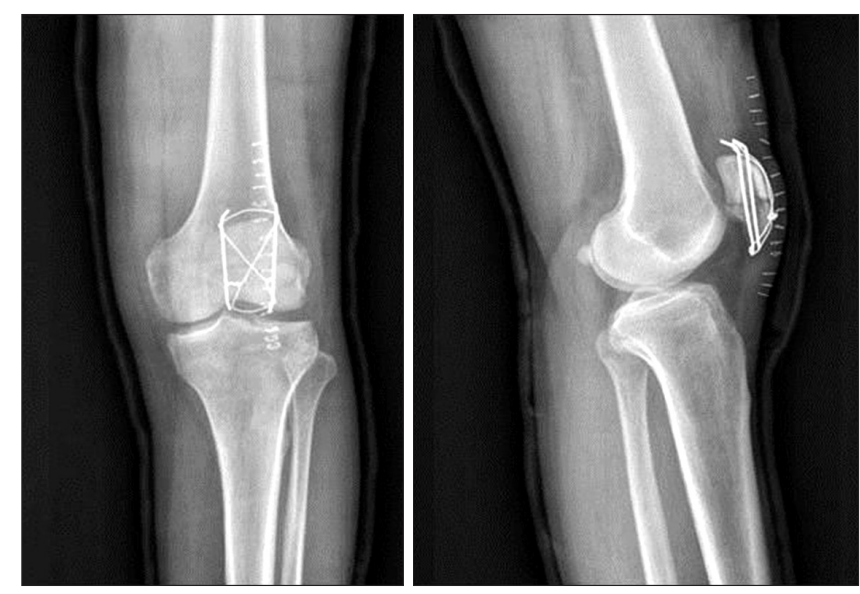

Fig. 3. Anteroposterior (left) and lateral (right) radiographs obtained after open reduction and internal fixation with tension band wiring for the patellar fracture. Postoperatively, a long leg cast was applied with the knee in full extension. The patient was satisfied with the regional nerve block and chose the same method as the anesthesia of choice for a future surgery. 
Table 1. Patient Data

\begin{tabular}{|c|c|c|c|c|c|c|c|}
\hline No. & $\begin{array}{l}\text { Age } \\
(\mathrm{yr})\end{array}$ & $\begin{array}{l}\text { Sex } \\
(\mathrm{M} / \mathrm{F})\end{array}$ & $\begin{array}{c}\text { Injury } \\
\text { mechanism }\end{array}$ & Fracture type & Operation & $\begin{array}{l}\text { Procedure time for } \\
\text { nerve block ( } \mathrm{min} \text { ) }\end{array}$ & $\begin{array}{l}\text { Pain-free duration } \\
\text { (min) }\end{array}$ \\
\hline 1 & 85 & M & Slip down & Closed & CRIF c screw & 18 & 550 \\
\hline 2 & 62 & M & Slip down & Closed & TBW & 14 & 420 \\
\hline 3 & 61 & M & Slip down & Closed & ORIF c K-wire & 15 & 550 \\
\hline 4 & 18 & M & Passenger in TA & Open, grade 3A & TBW & 15 & 600 \\
\hline 5 & 63 & $\mathrm{~F}$ & Slip down & Closed & TBW & 16 & 480 \\
\hline 6 & 68 & $\mathrm{~F}$ & Slip down & Closed & TBW & 17 & 520 \\
\hline 7 & 72 & M & Passenger in TA & Closed & TBW & 14 & 600 \\
\hline 8 & 20 & M & Sports injury & Closed & ORIF c screw & 16 & 660 \\
\hline 9 & 37 & M & Driver in TA & Open, grade 2 & CRIF c screw & 17 & 480 \\
\hline 10 & 63 & M & Slip down & Closed & TBW & 14 & 560 \\
\hline 11 & 70 & $\mathrm{~F}$ & Slip down & Closed & TBW & 17 & 650 \\
\hline 12 & 35 & $\mathrm{~F}$ & Passenger in TA & Closed & ORIF c K-wire & 16 & 450 \\
\hline 13 & 40 & M & Slip down & Closed & TBW & 17 & 650 \\
\hline 14 & 52 & $\mathrm{~F}$ & Passenger in TA & Closed & TBW & 15 & 410 \\
\hline 15 & 65 & M & Slip down & Open, grade 1 & TBW & 13 & 670 \\
\hline 16 & 64 & $\mathrm{~F}$ & Driver in TA & Closed & TBW & 13 & 540 \\
\hline 17 & 43 & M & Slip down & Closed & TBW & 17 & 620 \\
\hline 18 & 42 & $\mathrm{~F}$ & Driver in TA & Closed & TBW & 17 & 630 \\
\hline 19 & 53 & M & Sports injury & Closed & TBW & 14 & 490 \\
\hline 20 & 58 & M & Passenger in TA & Closed & TBW & 14 & 600 \\
\hline 21 & 29 & M & Driver in TA & Closed & TBW & 13 & 470 \\
\hline 22 & 46 & $\mathrm{~F}$ & Slip down & Closed & ORIF c K-wire & 14 & 610 \\
\hline 23 & 60 & M & Passenger in TA & Closed & TBW & 17 & 640 \\
\hline Mean & 52.4 & & & & & 15.3 & 558.7 \\
\hline
\end{tabular}

Open fractures were graded according to Gustilo and Anderson classification.

CRIF: closed reduction \& internal fixation, TBW: tension-band wiring, ORIF: open reduction \& internal fixation, TA: traffic accident.

cutaneous nerve, obturator nerve, and sciatic nerve were blocked. One orthopedic surgeon performed the nerve blocks in all patients using ACCUVIX V-20 ultrasound machine (Samsung Medison Co., Seoul, Korea). All patellar fracture surgeries were performed by a single surgeon with the patient placed in the supine position and a tourniquet applied on the mid-thigh level.

The procedure time of nerve block, the interval from the point of nerve block to the starting point of the operation, and the pain-free duration were measured. To evaluate the success rate of anesthesia, patients were asked to complete a questionnaire with respect to the following items: 1 ) interference, such as pain or discomfort of the operation site, during the overall operation: absolutely no interference (excellent), mild interference without disruption of the operation (good), moderate interference and completion of operation within the patient's tolerance (fair); se- vere interference disrupting completion of the operation (poor); 2) intraoperative knee pain (none, mild, moderate, and severe); and 3) pain induced by the tourniquet (none, mild, moderate, and severe). The specific values of the pain or discomfort rated according to the visual analog scale score were categorized as none (0), mild (1-3), moderate (4-7), and severe (8-10). Additionally, individual anesthetic complications and satisfaction with nerve block (highly satisfactory, excellent; satisfactory, good; moderate, fair; unsatisfactory, poor) were evaluated. The choice of future anesthetic method was investigated on the assumption that the same operation or a metal removal operation would be performed in the future.

Intramuscular injection of pethidine $\mathrm{HCl} 25 \mathrm{mg}$ was performed immediately before entering the surgery room to provide intraoperative analgesia. Midazolam $5 \mathrm{mg}$ was prepared for patients 
with anxiety or intense twilight anesthesia, which refers to a sedated state with only mild dosage of general anesthesia applied to the patient. Due to the risk of toxicity or complications after injection of midazolam, the antidote (flumazenil, $0.5 \mathrm{mg}$ ) was also prepared $^{14-16)}$. Vital signs and oxygen saturation were checked during the surgery.

In cases where completion of the operation appeared impossible due to severe interference, additional local anesthetics were injected into the same site if the pain was localized in the operation site. If the pain or discomfort was localized in the tourniquet area, we reduced the tourniquet pressure gradually until the pain was relieved. We had been planning to convert the anesthesia method to general or spinal anesthesia if none was effective, but there was no case that necessitated a conversion.

\section{Ultrasound-Guided Nerve Block Technique and Intraoperative Observation}

A mixture of $1 \%$ lidocaine $(30 \mathrm{~mL})$ and $0.75 \%$ ropivacaine $(20$ $\mathrm{mL}$ ) in a 1.5:1 ratio was loaded into a syringe and prepared by connecting a 23 gauge $(G)$ spinal needle with a venous catheter. The patient was positioned in the supine position. For femoral nerve block, after identification of the anatomical structure of the femoral vein, femoral artery, and femoral nerve using ultrasound at the femoral triangle in the distal part of the inguinal ligament, an injection was performed using the prepared $23 \mathrm{G}$ spinal needle. Under ultrasound guidance, the analgesics were injected when the tip of the needle was located around the epineurium. For every $2 \mathrm{~mL}$ of insertion, blood regurgitation was checked to prevent direct influx into blood vessels. On average, 12 to 25 $\mathrm{mL}$ of the solution was injected (Fig. 4A). For the lateral femoral cutaneous nerve block, the ultrasound was used to probe downward into the anterior superior iliac spine area and confirm the location of the lateral femoral cutaneous nerve. Under ultrasound guidance, after the $23 \mathrm{G}$ spinal needle was inserted in a lateral to medial direction, 7 to $8 \mathrm{~mL}$ of the solution was injected around the nerve while checking for blood reflux with every $2 \mathrm{~mL}$ of injection (Fig. 4B). For the obturator nerve block, after the leg was abducted, the ultrasound was placed in the inferomedial inguinal crease. All branches of the obturator nerve were observed between the adductor longus and adductor brevis after the obturator artery and veins were located by color Doppler due to the difficulty of visualizing this small nerve. The posterior branch of the obturator nerve was then located between the adductor brevis and adductor magnus. The $23 \mathrm{G}$ spinal needle was inserted from lateral to medial, and 7 to $8 \mathrm{~mL}$ of the solution was injected around the nerve, checking for blood reflux with every $2 \mathrm{~mL}$ of injection (Fig. 4C). For the sciatic nerve blockade, the patient's posture was adjusted, flexing the hip joint 30 to 45 degrees in the supine position so that the ultrasound probe could approach the posterior thigh. After verification of the anatomical locations of the popliteal artery, popliteal vein, tibial nerve, and common peroneal nerve in the popliteal area by ultrasound, the region in which the tibial nerve and common peroneal nerve merge with the sciatic nerve was confirmed while moving the ultrasound probe to the proximal femoral region. Under ultrasound guidance, the $23 \mathrm{G}$ spinal needle was inserted from lateral to medial at the posterior border of the iliotibial tract, and 12 to $25 \mathrm{~mL}$ of the solution was injected while checking for blood reflux with every $2 \mathrm{~mL}$ of injection (Fig. 4D). It is important to inject the analgesics with a "doughnut-ring" technique around the epineurium, checking the tip of needle by ultrasound (Fig. 5). There is no specific guideline for determining the proper injection dosage.

\section{Results}

The mean procedure time for the nerve block was 15.3 minutes (range, 13 to 18 minutes). The mean interval between the ending point of nerve block and starting point of the operation was 113.5 minutes (range, 15 to 276 minutes), and the mean pain-free duration time was 558.7 minutes (range, 410 to 670 minutes) (Table 1). We proceeded with the operation after the injection of midazolam in one patient who had felt pain during the pain-sensation test immediately before surgery and in another patient who had wanted intense twilight anesthesia. There was no case of conversion to general anesthesia or spinal anesthesia due to incomplete anesthesia. Regarding the evaluation of the success of anesthesia, interference with overall anesthesia was assessed as excellent in 19 patients $(82.6 \%)$ and good in 4 patients (17.4\%) (Table 2). Intraoperative knee pain was provoked in two patients (8.7\%): one in the anterior part and the other in the lateral femoral condylar area (Table 2). Tourniquet pain occurred in three patients: two patients complained of mild pain but tolerated the tourniquet pressure and the other complained of severe pain, which led to removal of the tourniquet during the remainder of the surgery (Table 2). There were no severe complications such as hypotension, supraventricular tachycardia, analgesic toxicity, hematoma, or infection around the injection area. Nerve block satisfaction was excellent in 17 patients (74\%), good in five patients $(21.7 \%)$, and unsatisfactory in one patient (4.3\%) (Table 2). Twenty-two patients (93.8\%) chose the lower-extremity nerve block under ultrasound guidance and only one chose general anesthesia as the preferred anesthetic method under the assumption that they 

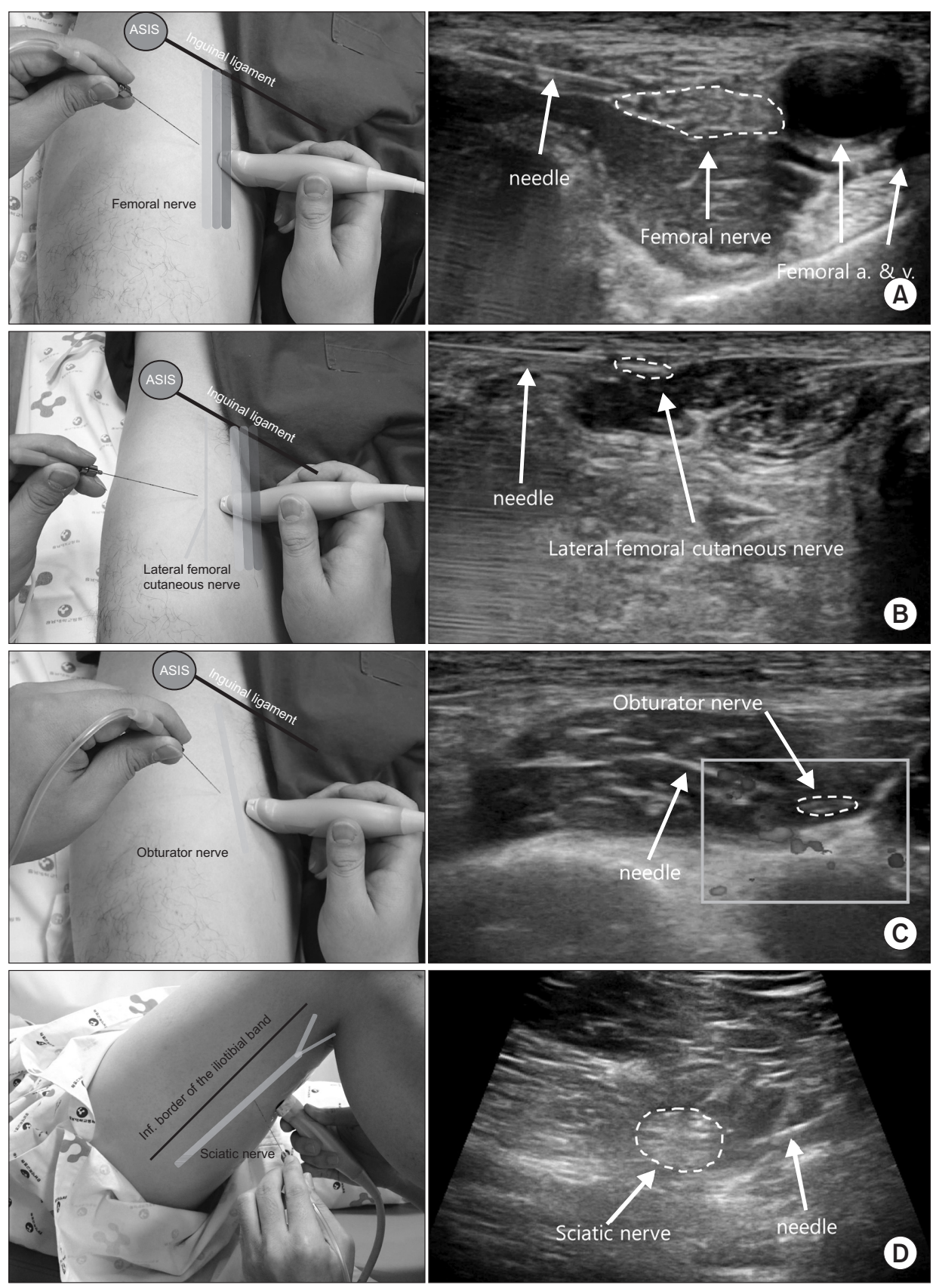

D)
Fig. 4. Photographs and ultrasound images of the nerve block procedure. (A) Femoral nerve. (B) Lateral femoral cutaneous nerve. (C) Obturator nerve. (D) Sciatic nerve. ASIS: anterior superior iliac spine, a.: artery, v.: vein; Inf.: inferior.
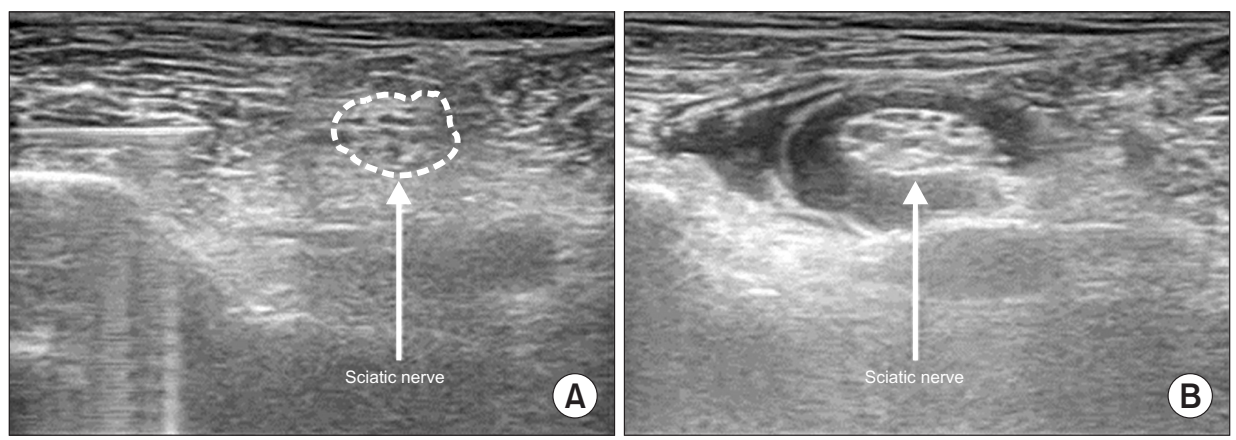

Fig. 5. (A) Ultrasound image showing the left sciatic nerve at the mid-thigh level proximal to the popliteal fossa. (B) Ultrasound image showing the anesthetic surrounds the left sciatic nerve after injection (doughnut ring sign). 
would undergo the same operation or a metal removal operation in the future (Table 3). The patient who chose general anesthesia was the patient who had felt mild pain in the anterior part of the knee joint during surgery and had reported severe tourniquet pain so that the surgery had been continued after decreasing the tourniquet pressure (Table 3). Perioperative vital signs and oxygen saturation showed no abnormality.

Table 2. Satisfaction with Nerve Block

\begin{tabular}{lc}
\hline Degree & No. (\%) \\
\hline Excellent & $17(74.0)$ \\
Good & $5(21.7)$ \\
Fair & $0(0)$ \\
Poor & $1(4.3)$ \\
\hline
\end{tabular}

\section{Discussion}

The knee joint has a much more complicated nerve distribution than does the foot and ankle joint. The major four nerves of the knee joint are the femoral nerve, sciatic nerve, lateral femoral cutaneous nerve and obturator nerve. The femoral nerve from L2-4 gives off the anterior cutaneous branch, the articular branch to the knee, and the saphenous nerve. The anterior cutaneous branch that comprises the intermediate cutaneous branch and the medial cutaneous branch innervates the sensory function of the anterior and lateral thigh. The articular branch to the knee innervates the anterior knee joint, medial articular capsule, and sensory function of the synovium. The saphenous nerve, which is the largest and longest among the three branches, gives off the infrapatellar branch and dominates the pain sensation of the patella and knee joint. The sciatic nerve, which originates from L4-5 and S1-3, divides into the tibial nerve and the common

Table 3. Patient Clinical Data

\begin{tabular}{|c|c|c|c|c|c|c|c|}
\hline No. & $\begin{array}{l}\text { Age } \\
(\mathrm{yr})\end{array}$ & $\begin{array}{c}\text { Sex } \\
(\mathrm{M} / \mathrm{F})\end{array}$ & $\begin{array}{l}\text { Interference } \\
\text { in operation }\end{array}$ & Intraoperative pain & $\begin{array}{l}\text { Tourniquet } \\
\text { pain }\end{array}$ & Satisfaction & $\begin{array}{l}\text { Patient's choice } \\
\text { for future anesthesia }\end{array}$ \\
\hline 1 & 85 & M & Excellent & $(-)$ & $(-)$ & Excellent & NB \\
\hline 2 & 62 & M & Excellent & $(-)$ & $(-)$ & Excellent & NB \\
\hline 3 & 61 & M & Good & Mild (LFC area) & $(-)$ & Good & NB \\
\hline 4 & 18 & M & Excellent & $(-)$ & $(-)$ & Good & NB \\
\hline 5 & 63 & $\mathrm{~F}$ & Excellent & $(-)$ & $(-)$ & Excellent & NB \\
\hline 6 & 68 & $\mathrm{~F}$ & Excellent & $(-)$ & $(-)$ & Good & NB \\
\hline 7 & 72 & M & Excellent & $(-)$ & $(-)$ & Excellent & NB \\
\hline 8 & 20 & M & Excellent & $(-)$ & $(-)$ & Good & NB \\
\hline 9 & 37 & M & Excellent & $(-)$ & $(-)$ & Excellent & NB \\
\hline 10 & 63 & M & Excellent & $(-)$ & $(-)$ & Excellent & NB \\
\hline 11 & 70 & $\mathrm{~F}$ & Good & Mild (anterior-surface) & Severe & Poor & General \\
\hline 12 & 35 & $\mathrm{~F}$ & Excellent & $(-)$ & $(-)$ & Excellent & NB \\
\hline 13 & 40 & M & Excellent & $(-)$ & $(-)$ & Excellent & NB \\
\hline 14 & 52 & $\mathrm{~F}$ & Excellent & $(-)$ & $(-)$ & Excellent & NB \\
\hline 15 & 65 & M & Excellent & $(-)$ & Mild & Excellent & NB \\
\hline 16 & 64 & $\mathrm{~F}$ & Excellent & $(-)$ & $(-)$ & Excellent & NB \\
\hline 17 & 43 & M & Excellent & $(-)$ & $(-)$ & Excellent & NB \\
\hline 18 & 42 & $\mathrm{~F}$ & Excellent & $(-)$ & $(-)$ & Excellent & NB \\
\hline 19 & 53 & M & Excellent & $(-)$ & Mild & Excellent & NB \\
\hline 20 & 58 & M & Excellent & $(-)$ & $(-)$ & Excellent & NB \\
\hline 21 & 29 & M & Excellent & $(-)$ & $(-)$ & Excellent & NB \\
\hline 22 & 46 & $\mathrm{~F}$ & Good & $(-)$ & $(-)$ & Good & NB \\
\hline 23 & 60 & M & Good & $(-)$ & $(-)$ & Excellent & NB \\
\hline
\end{tabular}

NB: nerve block, LFC: lateral femoral condyle. 
peroneal nerve. The tibial nerve gives off branches to the medial sural cutaneous nerve and an articular branch to the knee, which innervates the sensory function of the posteromedial calf and the anterior articular capsule. The lateral femoral cutaneous nerve originates from L2-3 and divides into the anterior and posterior branches functioning in proprioception of the anterolateral thigh and sensation of the posterolateral thigh. The obturator nerve originates from L2-4 and penetrates the obturator foramen, then divides into the anterior and posterior branches. The anterior branch of the obturator nerve, which becomes the cutaneous branch, innervates the inferomedial thigh, and the posterior branch, which becomes the articular branch to the knee, innervates the sensory function of the articular capsule. The abovementioned four nerves (femoral nerve, sciatic nerve, lateral femoral cutaneous nerve, and obturator nerve) are closely related to pain in the knee joint ${ }^{17-20)}$.

Theoretically, considering the distribution of the major four nerves mentioned above, a precise nerve block of them would allow anesthesia for surgery around the knee. Winnie et al. ${ }^{21)} \mathrm{em}-$ phasized the " 3 -in-1 block" in which it is possible to anesthetize the femoral nerve, obturator nerve, and lateral femoral cutaneous nerve because the fascial sheath envelopes the femoral nerve farther from the lumbar plexus. However, in reality, total blockage of the knee was possible in as low as $38 \%$ to $56 \%$ of the cases ${ }^{21,22)}$. In Ritter's cadaver research, injected methylene blue did not reach the lumbar plexus or the obturator nerve, but some of it reached the lateral femoral cutaneous nerve $\mathrm{e}^{23)}$. Considering these results, we assumed that an additional anesthesia of the obturator nerve is necessary for regional block of the medial knee joint. The fournerve block technique allowed us to successfully perform the surgery for patellar fracture.

In older patients with medical problems such as diabetes or cardiovascular disease, the mortality associated with general anesthesia or spinal block for surgery of the lower extremity is reported as 15 in $10,000^{4}$. Complications of general anesthesia include postoperative pain, nausea, vomiting, and respiratory problems, and those associated with spinal block include headache, hypotension, decreased bowel movements, urinary retention, and back pain ${ }^{24-26)}$. In contrast, our nerve block technique was associated with fewer complications and effective postoperative pain control considering the average pain-free duration of 558.7 minutes (range, 410 to 670 minutes). General anesthesia also requires at least 8 hours of nil per os time for surgery, which the nerve block technique does not require. Since orthopedic surgeons are familiar with neurovascular anatomy, it can be easily performed by themselves. Fortunately, our patients have not experienced any weakness of the muscles after the nerve block. So, we think ultrasound-guided nerve block is safe especially for older patients and the risk of general and spinal anesthesia can be avoided.

In reality, nonetheless, nerve block is not commonly used because of the risk of conversion to general anesthesia or spinal block in cases of inaccurate block. However, ultrasound has improved the success of anesthesia by allowing for more accurate injection around nerves, a lower dose of anesthetic drugs, and less nerve damage ${ }^{7,8)}$. Thus, we believe this problem associated with nerve block can be resolved by ultrasound guidance. The clinical data of our study showed nearly no disruption of the surgery, as indicated by the findings of absolutely no interference (excellent) in 19 patients $(82.6 \%)$ and mild interference without disruption of the operation (good) in 4 patients (17.4\%), no intraoperative pain in 21 patients $(91.3 \%)$, and continuance of the operation without tourniquet pain in 20 patients (87\%). Moreover, 22 patients (95.7\%) reported their anesthetic satisfaction level was above good and chose an ultrasound-guided nerve block as the preferred future anesthetic method.

Regarding the one case that suffered from severe pain, we attributed it to the patient's high sensitivity to pain. The pain was mainly located at the tourniquet site and was relieved when the pressure of the tourniquet was decreased.

The strength of this study is that both the ultrasound-guided lower extremity nerve block and the patellar surgery were performed by the same orthopedic surgeon, which has merit in terms of cost-effectiveness. Additionally, the lower extremity nerve block, which was previously restricted to foot and ankle surgery, was also shown to be effective in patellar surgery.

The weakness of this study is the inability to generalize the results; the small study population size may be the reason why no complication was observed in association with the ultrasoundguided lower extremity nerve blockade. In addition, this was not a comparative study involving other anesthetic techniques. Therefore, comparative studies involving a larger number of patients with consideration of these limitations should be performed.

\section{Conclusions}

In this study, ultrasound-guided lower extremity nerve block performed for patellar fracture surgery appeared to be an effective anesthetic method. Considering that even inexperienced ultrasound users can become familiar with ultrasound-guided nerve block within 5 subsequent trials ${ }^{27)}$, we think that the nerve 
block technique can be a useful alternative to general or spinal anesthetic methods to avoid associated problems and complications.

\section{Conflict of Interest}

No potential conflict of interest relevant to this article was reported.

\section{References}

1. Sarrafian SK, Ibrahim IN, Breihan JH. Ankle-foot peripheral nerve block for mid and forefoot surgery. Foot Ankle. 1983; 4:86-90.

2. Hansen E, Eshelman MR, Cracchiolo A 3rd. Popliteal fossa neural blockade as the sole anesthetic technique for outpatient foot and ankle surgery. Foot Ankle Int. 2000;21:38-44.

3. Varitimidis SE, Venouziou AI, Dailiana ZH, Christou D, Dimitroulias A, Malizos KN. Triple nerve block at the knee for foot and ankle surgery performed by the surgeon: difficulties and efficiency. Foot Ankle Int. 2009;30:854-9.

4. Flood BM, Shah MV. Intravenous regional anaesthesia for lower limb orthopaedic surgery. Ann R Coll Surg Engl. 1988; 70:257.

5. Domingo-Triado V, Selfa S, Martinez F, Sanchez-Contreras D, Reche M, Tecles J, Crespo MT, Palanca JM, Moro B. Ultrasound guidance for lateral midfemoral sciatic nerve block: a prospective, comparative, randomized study. Anesth Analg. 2007;104:1270-4.

6. Triado VD, Crespo MT, Aguilar JL, Atanassoff PG, Palanca JM, Moro B. A comparison of lateral popliteal versus lateral midfemoral sciatic nerve blockade using ropivacaine $0.5 \%$. Reg Anesth Pain Med. 2004;29:23-7.

7. Marhofer P, Greher M, Kapral S. Ultrasound guidance in regional anaesthesia. Br J Anaesth. 2005;94:7-17.

8. Perlas A, Brull R, Chan VW, McCartney CJ, Nuica A, Abbas $\mathrm{S}$. Ultrasound guidance improves the success of sciatic nerve block at the popliteal fossa. Reg Anesth Pain Med. 2008;33:259-65.

9. Shaw AD, DiBartolo G, Clatworthy M. Daystay hamstring ACL reconstruction performed under regional anaesthesia. Knee. 2005;12:271-3.

10. Salinas FV, Liu SS, Mulroy MF. The effect of single-injection femoral nerve block versus continuous femoral nerve block after total knee arthroplasty on hospital length of stay and long-term functional recovery within an established clinical pathway. Anesth Analg. 2006;102:1234-9.

11. Kosel J, Bobik P, Siemiatkowski A. The use of regional anesthetic techniques in pain management in patients undergoing primary knee replacement. Ortop Traumatol Rehabil. 2012;14:315-28.

12. Luhmann SJ, Schootman M, Schoenecker PL, Gordon JE, Schrock C. Use of femoral nerve blocks in adolescents undergoing patellar realignment surgery. Am J Orthop (Belle Mead NJ). 2008;37:39-43.

13. Auroy Y, Benhamou D, Bargues L, Ecoffey C, Falissard B, Mercier FJ, Bouaziz H, Samii K. Major complications of regional anesthesia in France: the SOS Regional Anesthesia Hotline Service. Anesthesiology. 2002;97:1274-80.

14. Cabrera LS, Santana AS, Robaina PE, Palacios MS. Paradoxical reaction to midazolam reversed with flumazenil. J Emerg Trauma Shock. 2010;3:307.

15. Thurston TA, Williams CG, Foshee SL. Reversal of a paradoxical reaction to midazolam with flumazenil. Anesth Analg. 1996;83:192.

16. Piekarski JM, Rossmann JA, Putman J. Benzodiazepine reversal with flumazenil: a review of the literature. J Can Dent Assoc. 1992;58:307-10.

17. Horner G, Dellon AL. Innervation of the human knee joint and implications for surgery. Clin Orthop Relat Res. 1994;(301):221-6.

18. Rommel O, Finger L, Bos E, Eichbaum A, Jager G. Neuropathic pain following lesions of the infrapatellar branch of the femoral nerve: an important differential diagnosis in anterior knee pain. Schmerz. 2009;23:355-9.

19. Barton RS, Ostrowski ML, Anderson TD, Ilahi OA, Heggeness $\mathrm{MH}$. Intraosseous innervation of the human patella: a histologic study. Am J Sports Med. 2007;35:307-11.

20. Moore KL, Dalley AF, Agur AMR. Clinically oriented anatomy. 6th ed. Lobndon: Lippincott Williams \& Wilkins; 2009, p529-31.

21. Winnie AP, Ramamurthy S, Durrani Z. The inguinal paravascular technic of lumbar plexus anesthesia: the "3-in-1 block". Anesth Analg. 1973;52:989-96.

22. Chelly JE, Greger J, Gebhard R, Coupe K, Clyburn TA, Buckle R, Criswell A. Continuous femoral blocks improve recovery and outcome of patients undergoing total knee arthroplasty. J Arthroplasty. 2001;16:436-45.

23. Ritter JW. Femoral nerve "sheath" for inguinal paravascular lumbar plexus block is not found in human cadavers. J Clin Anesth. 1995;7:470-3.

24. Curatolo M, Orlando A, Zbinden A, Venuti FS. Failure rate 
116 Kim et al. Ultrasound-Guided Nerve Blockade for Patellar Fracture

of epidural anaesthesia for foot and ankle surgery: a comparison with other surgical procedures. Eur J Anaesthesiol. 1995;12:363-7.

25. Flaatten H, Raeder J. Spinal anaesthesia for outpatient surgery. Anaesthesia. 1985;40:1108-11.

26. Gold BS, Kitz DS, Lecky JH, Neuhaus JM. Unanticipated admission to the hospital following ambulatory surgery. JAMA. 1989;262:3008-10.

27. Kim SC, Hauser S, Staniek A, Weber S. Learning curve of medical students in ultrasound-guided simulated nerve block. J Anesth. 2014;28:76-80. 